Original article

\title{
Regulation of the oxidative balance with coenzyme Q10 sensitizes human glioblastoma cells to radiation and temozolomide
}

\author{
Javier Frontiñán-Rubio $^{\mathrm{a}, \mathrm{b}}$, Raquel María Santiago-Mora ${ }^{\mathrm{a}, \mathrm{b}}$, Consuelo María Nieva-Velasco ${ }^{\mathrm{a}, \mathrm{b}}$, \\ Gustavo Ferrín ${ }^{\mathrm{C}}$, Alicia Martínez-González ${ }^{\mathrm{d}}$, María Victoria Gómez ${ }^{\mathrm{e}}$, María Moreno ${ }^{\mathrm{e}}$, Julia Ariza ${ }^{\mathrm{f}}$, \\ Eva Lozano ${ }^{g}$, Jacinto Arjona-Gutiérrez ${ }^{\mathrm{h}}$, Antonio Gil-Agudo ${ }^{\mathrm{h}}$, Manuel De la Mata ${ }^{\mathrm{c}}$, Milica Pesic ${ }^{\mathrm{i}}$, \\ Juan Ramón Peinado ${ }^{\mathrm{a}, \mathrm{b}}$, José M. Villalba ${ }^{\mathrm{f}}$, Luis Pérez-Romasanta ${ }^{\mathrm{j}}$, Víctor M. Pérez-García ${ }^{\mathrm{d}}$, \\ Francisco J. Alcaín ${ }^{\mathrm{a}, \mathrm{b}}$, Mario Durán-Prado ${ }^{\mathrm{a}, \mathrm{b}, *}$
}

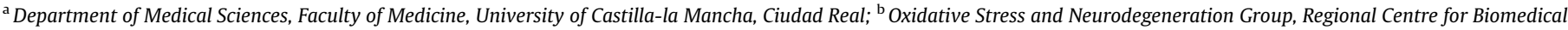

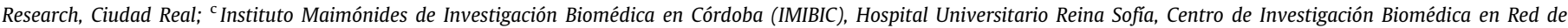

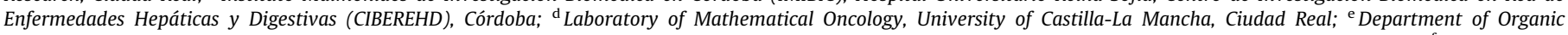

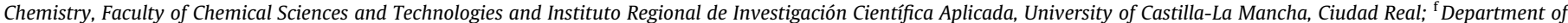

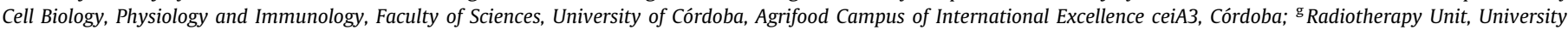

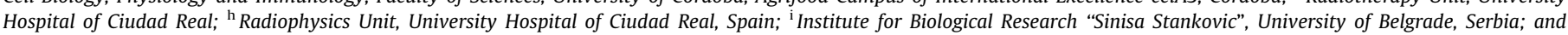
${ }^{\mathrm{j}}$ Radiation Oncology Department, University Hospital of Salamanca, Spain
\end{abstract}

\section{A R T I C L E I N F O}

\section{Article history:}

Received 14 June 2017

Received in revised form 5 April 2018

Accepted 29 April 2018

Available online $\mathrm{xxxx}$

\section{Keywords:}

Antioxidant capacity

Apoptosis

Glycolytic metabolism

Ionizing radiation

Reactive oxygen species

Ubiquinone

\begin{abstract}
A B S T R A C T
Objectives: To investigate how the modulation of the oxidative balance affects cytotoxic therapies in glioblastoma, in vitro.

Material and methods: Human glioblastoma U251 and T98 cells and normal astrocytes C8D1A were loaded with coenzyme Q10 (CoQ). Mitochondrial superoxide ion $\left(\mathrm{O}_{2}^{-}\right)$and $\mathrm{H}_{2} \mathrm{O}_{2}$ were measured by fluorescence microscopy. OXPHOS performance was assessed in U251 cells with an oxytherm Clark-type electrode. Radio- and chemotherapy cytotoxicity was assessed by immunostaining of $\gamma \mathrm{H} 2 \mathrm{AX}(24 \mathrm{~h}$ ), annexin $\mathrm{V}$ and nuclei morphology, at short $(72 \mathrm{~h}$ ) and long (15 d) time. Hif-1 $\alpha$, SOD1, SOD2 and NQO1 were determined by immunolabeling. Catalase activity was measured by classic enzymatic assay. Glutathione levels and total antioxidant capacity were quantified using commercial kits.

Results: CoQ did not affect oxygen consumption but reduced the level of $\mathrm{O}_{2}^{-}$and $\mathrm{H}_{2} \mathrm{O}_{2}$ while shifted to a pro-oxidant cell status mainly due to a decrease in catalase activity and SOD2 level. Hif- $1 \alpha$ was dampened, echoed by a decrease lactate and several key metabolites involved in glutathione synthesis. CoQtreated cells were twofold more sensitive than control to radiation-induced DNA damage and apoptosis in short and long-term clonogenic assays, potentiating TMZ-induced cytotoxicity, without affecting nontransformed astrocytes.

Conclusions: CoQ acts as sensitizer for cytotoxic therapies, disarming GBM cells, but not normal astrocytes, against further pro-oxidant injuries, being potentially useful in clinical practice for this fatal pathology.
\end{abstract}

(C) 2018 Elsevier B.V. All rights reserved. Radiotherapy and Oncology xxx (2018) xxx-xxx
Grade IV astrocytoma or glioblastoma multiforme (GBM) is the most common type of malignant brain tumor in adults [1]. The current therapeutic protocol for this pathology includes maximal safe surgery, radiotherapy and chemotherapy with temozolomide (TMZ), an alkylating agent and radiosensitizer [2,3]. Nevertheless, even patients receiving the standard of care die early with a med-

* Corresponding author at: Faculty of Medicine, University of Castilla-La Mancha, 13071 Ciudad Real, Spain.

E-mail address: mario.duran@uclm.es (M. Durán-Prado). ian survival of 14 months due to recurrence within the radiation field $[1,4,5]$.

Several evidences link GBM radioresistance with the mitochondrial pathophysiology and the over-production of radical oxygen species (ROS) scavengers, which lately determine a shift to an antioxidative balance [6-10]. GBM cells are very glycolytic even in normoxia: the so called "Warburg effect" [11]. In this setting, a high level of $\mathrm{O}_{2}^{--}$is produced and rapidly dismutated to $\mathrm{H}_{2} \mathrm{O}_{2}$, which is translocated to the cytosol, orchestrating multiple mechanisms leading to radioresistance [12-14]. High levels of $\mathrm{O}_{2}^{--}$and $\mathrm{H}_{2} \mathrm{O}_{2}$ are toxic and thus, GBM cells increase their antioxidant 
defenses as a survival mechanism, i.e. the levels of catalase and mitochondrial superoxide dismutase (SOD2) are increased [6,7].

The cytotoxic effect of ionizing radiation is mediated by the induction of ROS, leading to DNA and RNA damage and genomic instability [14]. Thus, the naturally increased level of catalase and SOD2 enzymes ameliorates radiation-induced DNA damage, contributing to resistance to radiation-induced cell damage $[6,15]$. Moreover, the increased level of reduced glutathione (GSH) also contributes to cell protection against ROS and, thus, participates in the resistance to ionizing radiation [16]. Indeed, there is a negative correlation between the level of GSH and sensitivity to ionizing radiation in a series of brain tumors including GBM [17]. GSH level is also related to resistance to TMZ and mediates several mechanisms of resistance development [18]. Furthermore, high lactate levels produced by aerobic glycolysis are also interconnected with radioresistance. Actually, lactate behaves as an antioxidant [19], being positively correlated with resistance to ionizing radiation [14].

Instead of a single factor, radioresistance is orchestrated by several enzymes and small molecules that are linked to the increased generation of ROS. Therefore, the simultaneous modulation of these ROS scavengers may be useful in GBM therapies. In this work, we explore the role of coenzyme $\mathrm{Q}_{10}(\mathrm{CoQ})$ in the mechanisms evoking radioresistance using two human GBM cell lines, U251 and T98, compared to non-transformed astrocytes C8D1A. CoQ is a lipophilic antioxidant that crosses the blood-brain barrier [20]. Besides, it is a component of the mitochondrial electron transport chain (ETC) that dampens the $\mathrm{O}_{2}^{--}$generated by complex I in dystrophic mitochondria [12]. Our results show that treatment of human U251 GBM cells with CoQ did not affect OXPHOS, but slightly increased oxygen consumption associated with the mitochondrial complex I, which was paralleled by a decrease in the level of mitochondrial $\mathrm{O}_{2}^{-}$and cytosolic $\mathrm{H}_{2} \mathrm{O}_{2}$. Conversely, these reactive species were increased upon irradiation in GBM cells, but not in non-transformed astrocytes. Indeed, CoQ sensitized cells to radiation-induced DNA damage and apoptosis both in short- and long-term clonogenic assays. These effects are mediated by a shift in the oxidative balance toward pro-oxidant conditions, which relies on the reduction in catalase activity, a decrease in SOD2 level and a cut down in intracellular lactate and key metabolites involved in glutathione synthesis, which could be related to the reduced level of Hif- $1 \alpha$. On the other hand, neither SOD1 nor NQO1 levels were altered. These changes result in a reduction in the total antioxidant cellular capacity and a shift to a pro-oxidant cellular state that disarms GBM cells against further pro-oxidant injuries induced by standard therapies, without affecting nontransformed astrocytes. Our results indicate that CoQ combined with radiation and TMZ has a promising potential for improving the current therapeutic protocol for GBM.

\section{Material and methods}

\section{Reagents}

Coenzyme $\mathrm{Q}_{10}$ was provided by Kaneka Corporation. TMZ, Hoechst, crystal violet, EDTA, methanol, DMSO, $\mathrm{dH}_{2} \mathrm{O}$, Tris- $\mathrm{HCl}$, DTT and other general reagents were acquired from Sigma-Aldrich.

\section{Cell culture and irradiation}

Human GBM U251 and T98 and non-transformed astrocytes C8D1A were obtained from ATCC and maintained under normoxia in DMEM (Sigma-Aldrich) at $37{ }^{\circ} \mathrm{C}$ and $5 \% \mathrm{CO}_{2}$. For irradiation purposes, cells were seeded in 24 well plates and pre-treated for $24 \mathrm{~h}$ with CoQ or vehicle (ethanol; control). Depending on the experiment, cells were treated with TMZ $(50 \mu \mathrm{M})$ or vehicle (DMSO) and again $24 \mathrm{~h}$ later cells were irradiated in a Gulmay D 3150 (NCA) at doses ranging between 1 and $16 \mathrm{~Gy}(1.211 \mathrm{~Gy} / \mathrm{min})$ at $100 \mathrm{kV}$ tube potential. Different parameters were evaluated immediately after irradiation $\left(\mathrm{O}_{2}^{--}\right.$and $\left.\mathrm{H}_{2} \mathrm{O}_{2}\right)$, at $24 \mathrm{~h}$ (DNA damage), at $96 \mathrm{~h}$ (apoptosis) or at 15d (colonies formation) of irradiation.

\section{OXPHOS performance}

Oxygen consumption in intact or digitonin-permeabilized cells was determined with an oxytherm Clark-type electrode (Hansatech Instruments, Norfolk, UK) as previously described [21]. Briefly, U251 cells were resuspended in culture medium or respiration buffer (10 $\mathrm{mM} \mathrm{MgCl}_{2}, 250 \mathrm{mM}$ Sucrose, $20 \mathrm{mM}$ HEPES pH 7.4, $1 \mathrm{mM}$ ADP, $2 \mathrm{mM} \mathrm{KH}_{2} \mathrm{PO}_{4}$ ), respectively. Oxygen consumption was recorded at $37{ }^{\circ} \mathrm{C}$ with stirring. $7.5 \mu \mathrm{M}$ carbonyl cyanide-4-(trifluor omethoxy)phenylhydrazone (FCCP) was used to uncouple respiration in intact cells. For polarographic measurements, cells were permeabilized with $1 \%$ digitonin $\left(1.2 \mathrm{ul} / 10^{6}\right.$ cells $)$ for $10 \mathrm{~min}$ at $37{ }^{\circ} \mathrm{C}$ and oxygen consumption was recorded after the addition of substrates and inhibitors for Complex I ( $5 \mathrm{mM}$ Glutamate plus $5 \mathrm{mM}$ Malate, and $2 \mu \mathrm{M}$ Rotenone), Complex II + III (5 mM Succinate plus $5 \mathrm{mM}$ Gliceraldehide-3-P, and $0.1 \mu \mathrm{M}$ Antimycin A) and Complex IV (1.2 mM TMPD, and $6 \mathrm{mM} \mathrm{KCN}$ ). Reactions were terminated by the addition of $6 \mathrm{mM} \mathrm{KCN}$ to assess any $\mathrm{O}_{2}$ consumption not derived from the respiratory chain.

\section{Single-cell determination of $\mathrm{O}_{2}^{-}$and $\mathrm{H}_{2} \mathrm{O}_{2}$}

Mitochondrial $\mathrm{O}_{2}^{--}$and total $\mathrm{H}_{2} \mathrm{O}_{2}$ levels were determined with MitoSOX and $\mathrm{H}_{2}$ DCFDA probes, respectively (Life Technologies). Cells were seeded in 96 well plates and incubated for $24 \mathrm{~h}$ with vehicle (control) or CoQ $(2.5-10 \mu \mathrm{M})$ and then irradiated as indicated above. Then, cells where immediately loaded for $30 \mathrm{~min}$ with $1 \mu \mathrm{M}$ MitoSOX or $\mathrm{H}_{2}$ DCFDA, washed in fresh medium and imaged in a Nikon TiU microscope ( $20 \times$ objective). Images were analyzed and processed with ImageJ software (NIH). Results are expressed as the percentage of cell signal $v s$. control (minimum 50 cells, $n=3)$.

\section{Determination of total antioxidant capacity}

Cells were seeded in 96 well plates and incubated for $24 \mathrm{~h}$ with vehicle (control) or CoQ $(5 \mu \mathrm{M})$. Total antioxidant capacity was determined in cell lysates and in culture media using a commercial kit, following the manufacturer's instructions (MAK187, SigmaAldrich). Results were expressed as $\mathrm{nmol} / \mu \mathrm{g}$ of protein $(n=4)$.

\section{Determination of DNA damage, apoptosis and viability}

Cells treated with CoQ and irradiated, after 24 and $72 \mathrm{~h}$ for DNA damage and apoptosis and viability assays, respectively, were fixed for $2 \mathrm{~min}$ in $4 \%$ para-formaldehyde (PFA), stained with $1 \mu \mathrm{g} / \mathrm{ml}$ Hoechst and immunolabeled for annexin V (1:500; BD Pharmingen) and $\gamma \mathrm{H} 2 \mathrm{AX}$ antibody (1:500; Santa Cruz Biotechnology). For $\gamma \mathrm{H} 2 \mathrm{AX}$ staining, cells were permeabilized for $2 \mathrm{~min}$ in ice-cold methanol after PFA fixation. Binding of primary antibodies was detected with fluorescence-labeled secondary antibodies conjugated with Alexa-594 (1:2000; Life Technologies). Apoptotic nuclei were determined from Hoechst-stained nuclei images according to morphometric criteria with Imagej. Those cells exhibiting normal, non-apoptotic, nuclei morphology were considered as viable. Results are shown as percentage of apoptotic $v$ s. total cells (at least 100 cells, $n=4)$. DNA damage was determined and represented as the number of $\gamma \mathrm{H} 2 \mathrm{AX}$ foci per cell (at least 100 cells, $n=4$ ). Apoptotic cells were determined according to annexin $\mathrm{V}$ level. Results 
were represented as the average fluorescent signal per cell (at least 100 cells, $n=4$ ).

\section{Clonogenic assays}

Cells, seeded at 200 cells/well in 24 well plates, were treated as indicated in paragraph above. At 15 days from irradiation, cells were fixed for $2 \mathrm{~min}$ in cold methanol and stained with $0.01 \%$ $(\mathrm{w} / \mathrm{v})$ crystal violet for $30 \mathrm{~min}$. Dishes were dried and colonies containing more than 50 individual cells determined using bright field microscopy with a Nikon TiU microscope $(2 \times$ objective) $(n=3)$.

\section{Sensitivity to exogenous $\mathrm{H}_{2} \mathrm{O}_{2}$}

Cells were seeded to subconfluence in 96 well plates and incubated for $24 \mathrm{~h}$ with vehicle (ethanol; control) or $5 \mu \mathrm{M}$ CoQ. Then, cells were treated with increasing concentrations of $\mathrm{H}_{2} \mathrm{O}_{2}$ (12.5-1 $00 \mu \mathrm{M})$ and $8 \mathrm{~h}$ later cells were fixed and permeabilized for 2 min in ice-cold methanol and stained with $1 \mu \mathrm{g} / \mathrm{ml}$ Hoechst. The number of adhered cells was counted from fluorescence microscopy images. Results were computed as the percentage of cells vs. control (at least 300 cells, $n=5$ ).

\section{Catalase activity}

Cells were seeded in 6 well plates and incubated for $24 \mathrm{~h}$ with vehicle (ethanol; control) or $5 \mu \mathrm{M} \mathrm{CoQ}$. Proteins were extracted with a lysis buffer (Tris-HCl $10 \mathrm{mM}$, EDTA $1 \mathrm{mM} \&$ DTT $0.1 \mathrm{mM}$ ). Catalase activity was quantified by spectrophotometric assays as previously described elsewhere [22] and the fold change in catalase activity vs. control conditions $(n=3)$ computed.

\section{Quantification of SOD1, SOD2, NQO1 and Hif- $1 \alpha$}

Cells were seeded in 6 well plates and incubated for $48 \mathrm{~h}$ with vehicle (ethanol; control) or $5 \mu \mathrm{M} \mathrm{CoQ}$. Proteins were extracted with SDS-DTT buffer. The level of SOD2, SOD1, NQO1 and Hif-1 $\alpha$ (1:1000 dilution, Santa Cruz Biotechnology) was quantified by western blot as described before [23]. Results are expressed as the mean band intensity $v s$. actin and normalized to control condition $(n=4)$. The level of Hif- $1 \alpha$ was also measured by quantitative immunocytochemistry and epifluorescence and the results expressed as the mean cell-fluorescence intensity normalized to control (at least 50 cells, $n=4$ ).

\section{Determination of metabolites by Nuclear Magnetic Resonance (NMR)}

NMR experiments were carried out on a Varian VNMRS-400 NMR system using a nanoprobe with rotors of $40 \mu \mathrm{L}$. 1D and 2D NMR experiments were recorded for peak identification. Chenomx Profiler (Chenomx Inc.) was used to assist in peak identification. TSP was used as internal standard for quantification of metabolites. The NMR spectra were processed with Mestrenova (Mestrelab Research). Cells were grown onto $25 \mathrm{~cm} 2$ flasks and treated for $24 \mathrm{~h}$ with vehicle (ethanol; control) or $5 \mu \mathrm{M}$ CoQ. The level of lactate, glutamate, glycine, serine and glutamine was assessed as described before [24].

\section{Glutathione determination}

Cells were grown in $25 \mathrm{~cm}^{2}$ flasks and incubated for $24 \mathrm{~h}$ with vehicle (ethanol; control) or $5 \mu \mathrm{M} \mathrm{CoQ}$. Reduced (GSH) and oxidized (GSSG) glutathione were determined as described before [25]. Both absolute GSH and GSSG values and the GSSG/GSH ratio $(n=4)$ were computed.

\section{Radiobiological parameter in the dose-response curves}

Dose-response curves for cell viability were fit using a Linealquadratic model for the surviving fraction $S F(D)=\exp \left(-\alpha D-\beta D^{\wedge} 2\right)$. $\alpha$ and $\beta$ were fit using least squares methods from the data on response to intermediate doses considering realistic values for $\alpha / \beta$.

\section{Statistical analysis}

Data are expressed as mean \pm S.E.M. obtained from, at least, three independent experiments. Statistical analysis was carried out with GraphPad Prism 6, using Student's t-test or a one-way ANOVA (Kruskal-Wallis' test) followed by a statistical test for multiple comparisons (Dunn's test). Differences were considered significant at $p<0.05$. Results were analyzed for synergism using the combination index method calculated by CompuSyn V 1.0, obtaining the values for the coefficient of interaction (CI; 0.1-0.3, strong synergism; 0.3-0.7, synergism; 0.7-0.85, moderate synergism; $0.85-0.9$, slight synergism and $0.9-1$, nearly additive) and the fractional effect (FE).

\section{Results}

CoQ potentiates radiation-induced rise in $\mathrm{O}_{2}^{--}$and $\mathrm{H}_{2} \mathrm{O}_{2}$ levels and decreases the total antioxidant cell capacity in GBM cells

We first explored the effect of the incubation of human U251 and T98 cells and non-transformed astrocytes C8D1A with $5 \mu \mathrm{M}$ $\mathrm{CoQ}$ on the levels of mitochondrial $\mathrm{O}_{2}^{-}$and $\mathrm{H}_{2} \mathrm{O}_{2}$ both under basal conditions and upon irradiation. Our results show that a $24 \mathrm{~h}$ pretreatment with CoQ reduced the levels of both reactive species by $45 \%$ and $35 \%$, respectively, in non-irradiated U251 cells (Fig. 1A). A similar albeit lower reduction (of about $15 \%$ and $14 \%$ respectively) was observed in T98 cells (Fig. 2B), whereas no significant decrease was detected in non-transformed astrocytes C8D1A (Fig. 1C). However, U251 cells treated with CoQ showed significantly higher levels of $\mathrm{O}_{2}^{--}$and $\mathrm{H}_{2} \mathrm{O}_{2}$ than untreated cells after irradiation. In this setting, mitochondrial $\mathrm{O}_{2}^{-}$was increased by 1.2 and 1.4 -fold for 2 and $4 \mathrm{~Gy}$, respectively, in CoQ-treated vs. non-treated cells (Fig. $1 \mathrm{~A}$ and Supplementary Fig. 1). Similar results were obtained for $\mathrm{H}_{2} \mathrm{O}_{2}$. In CoQ-treated cells, $\mathrm{H}_{2} \mathrm{O}_{2}$ levels increased 1.35 -fold at 2 Gy and 1.3-fold at $4 \mathrm{~Gy} v$ s. non-treated cells (Fig. 1A). Comparable results were obtained for T98 cells, being significant only at $4 \mathrm{~Gy}$ dose for $\mathrm{O}_{2}^{--}$(Fig. 1B). Opposingly, levels of both $\mathrm{O}_{2}^{--}$and $\mathrm{H}_{2} \mathrm{O}_{2}$ were significantly reduced after irradiation in CoQ-treated nontransformed astrocytes (Fig. 1C). This dual effect of CoQ observed in GBM cells was due to the modulation of total antioxidant cell capacity. Indeed, U251 and T98 cells treated with CoQ showed a $15 \%$ decrease in the total antioxidant capacity $v$ s. non-treated cells, which reflects a shift to a pro-oxidant cell state, whereas no change was detected in the culture media (Fig. 1D and E).

\section{CoQ enhances radiation-induced DNA damage and apoptosis}

Since incubation of GBM cells with CoQ increased the level of radiation-induced $\mathrm{O}_{2}^{-}$and $\mathrm{H}_{2} \mathrm{O}_{2}$, we next studied the effect of this compound on DNA damage in control and CoQ-treated U251 cells, by measuring the number of $\gamma-\mathrm{H} 2 \mathrm{AX}$ foci per cell after irradiation. We observed an average of 3.5 positive foci/cell in irradiated control cells, and preincubation with $5 \mu \mathrm{M}$ CoQ for $24 \mathrm{~h}$ increased by 2.7 -fold the number of positive $\gamma$-H2AX foci at $24 \mathrm{~h}$ from irradiation (Supplementary Fig. 2A). This exacerbation of DNA damage was translated into an increased pro-apoptotic effect of radiation, measured as annexin $\mathrm{V}$ exposure at the external hemi-layer of the plasma membrane. Radiation induced an average of 7.94 relative fluorescence units (RFU) in irradiated control cells and this value was increased by 13.6 -fold in cells that had been preincu- 

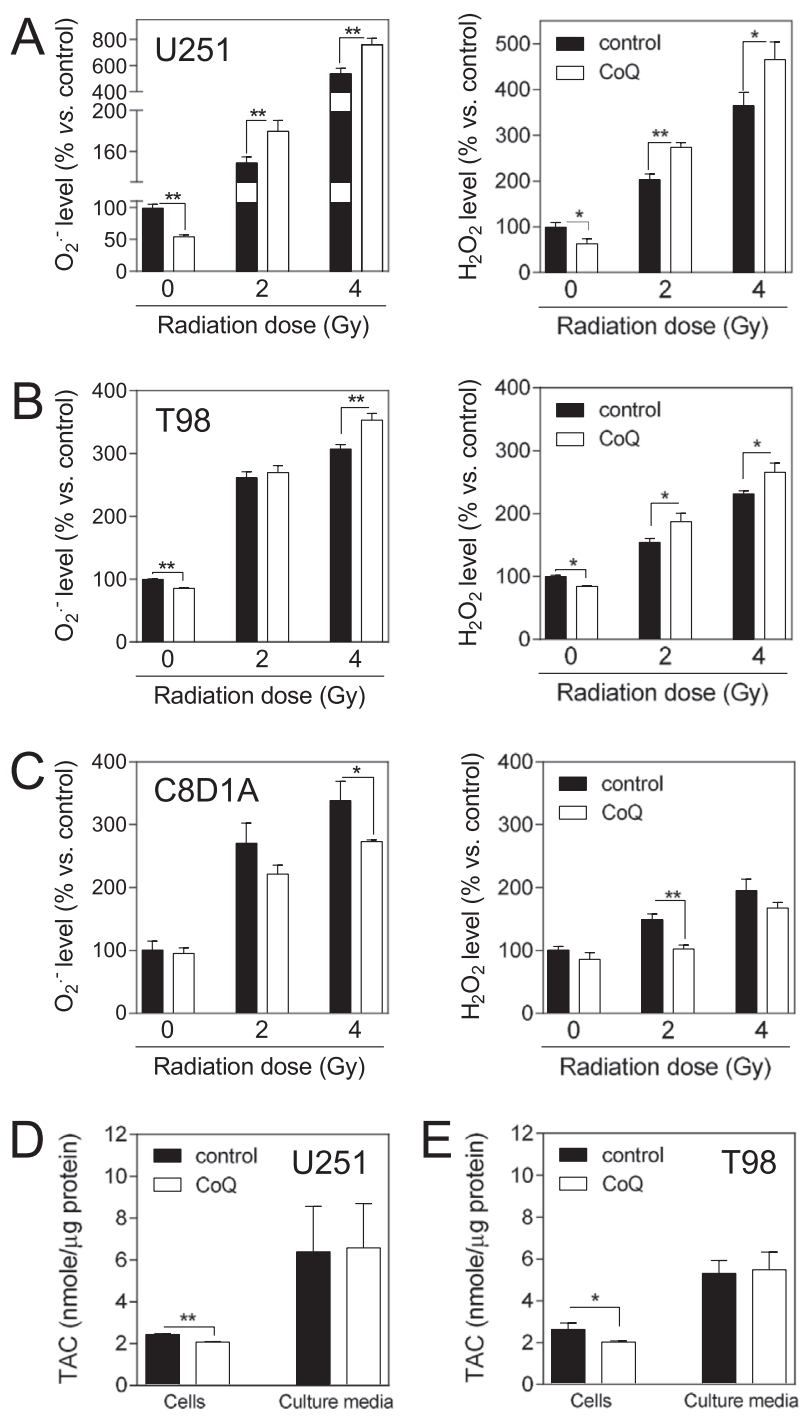

Fig. 1. Effect of exogenous $\mathrm{CoQ}$ on oxidative stress and radiation-induced cell damage in human GBM cells and non-transformed astrocytes, in vitro. Cells were incubated with $5 \mu \mathrm{M} \mathrm{CoQ}$ for $24 \mathrm{~h}$ and then irradiated $(0-4 \mathrm{~Gy}) \cdot \mathrm{O}_{2} \cdot-(\mathrm{A}-\mathrm{C}$, left graphs) and $\mathrm{H}_{2} \mathrm{O}_{2}$ (A-C, right graphs) levels were quantified by fluorescence microscopy with the probes MitoSOX and $\mathrm{H}_{2}$ DCFDA, respectively. Results are expressed as the percentage of cell signal $v s$. control, $0 \mathrm{~Gy}$, non-treated and nonirradiated for GBM U251 and T98 cells (A and B) and non-transformed astrocytes C8D1A (C). $\min =50$ cells, $n=3,{ }^{*} p<0.05 ;{ }^{* *} p<0.005$. Total antioxidant cell and supernatant capacities, TAC, was determined by colorimetry in GBM U251 and T98 cells ( $\mathrm{D}$ and $\mathrm{E}$ ). Results are expressed as nmol normalized to protein concentration, quantified by BCA. $n=4,{ }^{* *} p<0.005$

bated for $24 \mathrm{~h}$ with $5 \mu \mathrm{M} \mathrm{CoQ}$ and measured $96 \mathrm{~h}$ after irradiation (Supplementary Fig. 2B). Indeed, this increase in annexin V staining and apoptosis was translated into a decrease in cell viability (Fig. 2A, left graph). Radiation alone reduced GBM cell viability by $35 \%$ and $50 \%$ at 2 and $4 \mathrm{~Gy}$, respectively, and preincubation with CoQ diminished cell viability by $60 \%$ and $70 \%$ for the same radiation doses (Fig. 2A, left graph). Indeed, the $\mathrm{IC}_{50}$ was reduced from 2.5 in control conditions to $1.3 \mathrm{~Gy}$ in cells preincubated with $\mathrm{CoQ}$ (Fig. 1F). Thus, CoQ almost doubled the cytotoxic effect of radiation measured after $96 \mathrm{~h}$. The radiobiological response parameters for both curves were $\alpha=0.1100$ and $\beta=0.0120$ (CoQ-treated) and $\alpha$ $=0.02$ and $\beta=0.12$ (control) suggesting much weaker singlestrand break repair mechanisms mediated by CoQ (term linear in the dose D). The data were very well described with the standard Linear-quadratic model for the surviving fraction. This reduction in cell viability exerted by CoQ upon radiation was reproduced in T98 cells (Fig. 2A, middle graph), whereas no effect was shown in non-transformed C8D1A astrocytes (Fig. 2A, right graph).

\section{CoQ improves the long-term cytotoxic effect of radiation}

To check the remaining viable cells' ability to regrow, we performed clonogenic assays. Human GBM cells were preincubated with vehicle or CoQ $24 \mathrm{~h}$ before irradiation and were then irradiated with a single dose of 1,4 or $8 \mathrm{~Gy}$. Cells were cultured for 15 days and then stained to count the number of clones in each well. In control U251 and T98 cells, radiation alone reduced the surviving fraction by $15 \%$ and $35 \%$ at $4 \mathrm{~Gy}$ and by $60 \%$ and $68 \%$ at $8 \mathrm{~Gy}$, respectively (Fig. 2B, left and middle graphs and Supplementary Fig. $3 \mathrm{~A}$ and $\mathrm{B}$ ). Preincubation with $\mathrm{CoQ}$ reduced the surviving fraction by $48 \%$ and $55 \%$ for $4 \mathrm{~Gy}$ and by $81 \%$ and $76 \%$ at $8 \mathrm{~Gy}$, respectively, thus triplicating the effect obtained for control cells at $4 \mathrm{~Gy}$ (Fig. 2B, left and middle graphs). On the other hand, CoQ did not affect the surviving fraction in non-transformed C8D1A astrocytes, but even induced a slight, although statistically not significant, protective effect (Fig. 2B, left and middle graphs and Supplementary Fig. 3C). Our results show that the CoQ-mediated radiosensitization of GBM cells involves an exacerbation of lethal DNA damage that cannot be repaired by these tumor cells.

\section{CoQ does not affect oxygen consumption but reduces lactate and} Hif- $1 \alpha$ levels

As complex I in tumor cells dystrophic mitochondria generates high amounts of $\mathrm{O}_{2}^{-}$radicals [12] and our results have shown that CoQ diminishes the level of this radical species (Fig. 1A and B), we wondered if mitochondrial respiration was affected upon addition of the antioxidant. Incubation of GBM U251 cells with $5 \mu \mathrm{M} \mathrm{CoQ}$ did not modify neither endogenous nor uncoupled oxygen consumption (Fig. 3A), though it slightly increased oxygen consumption associated with complex I from 0.59 to $0.96 \mathrm{fmol} / \mathrm{min} /$ cell (Fig. 3B).

Considering that GBM are highly glycolytic and intracellular lactate level is involved in radioresistance $[11,14]$, we then measured the level of intracellular lactate in U251 cells treated for $24 \mathrm{~h}$ with vehicle (control) or $5 \mu \mathrm{M} \mathrm{CoQ}$ showing a decrease in lactate by $46 \% v s$. control (Fig. 3C). This decrease was paralleled by a 40 and 25\%-reduction in U251 and T98 cells, respectively, in the level of the transcription factor Hif- $1 \alpha$, the main inductor of glycolytic metabolism upon CoQ pretreatment (Fig. 3D and E). On the other hand, the level of Hif- $1 \alpha$ was not affected by CoQ treatment in non-transformed astrocytes C8D1A (Fig. 3F).

CoQ reduces catalase activity and the level of SOD2 but does not modify the levels of SOD1 or NQO1

Exacerbated ROS levels lead to an increase in the level of antioxidant phase II enzymes, including catalase and SOD2 [6,7]. Since CoQ reduced the total antioxidant cell capacity and increased the level of both $\mathrm{O}_{2}^{--}$and $\mathrm{H}_{2} \mathrm{O}_{2}$ in GBM cells after irradiation, we wondered if these phase-II antioxidant enzymes were downregulated. Incubation of human GBM cells with CoQ ranging from 2.5 to 10 $\mu \mathrm{M}$ reduced catalase activity between $35-50 \%$ and $25-50 \%$ in U251 and T98 cells, respectively, which was not affected in nontransformed astrocytes (Fig. 4A). Also, human GBM cells preincubated with $5 \mu \mathrm{M}$ CoQ were more sensitive than control cells to cytotoxicity of exogenous $\mathrm{H}_{2} \mathrm{O}_{2}$, obtaining $\mathrm{IC}_{50}$ values of 3 and 8 $\mu \mathrm{M}$ in $\mathrm{U} 251$ and 12.7 and $25.3 \mu \mathrm{M}$ in T98 for CoQ-treated or control cells, respectively, whereas no difference was found for nontransformed astrocytes C8D1A (Fig. 4B). Similarly, the level of SOD2 polypeptide was reduced by $40 \%$ after CoQ treatment in 

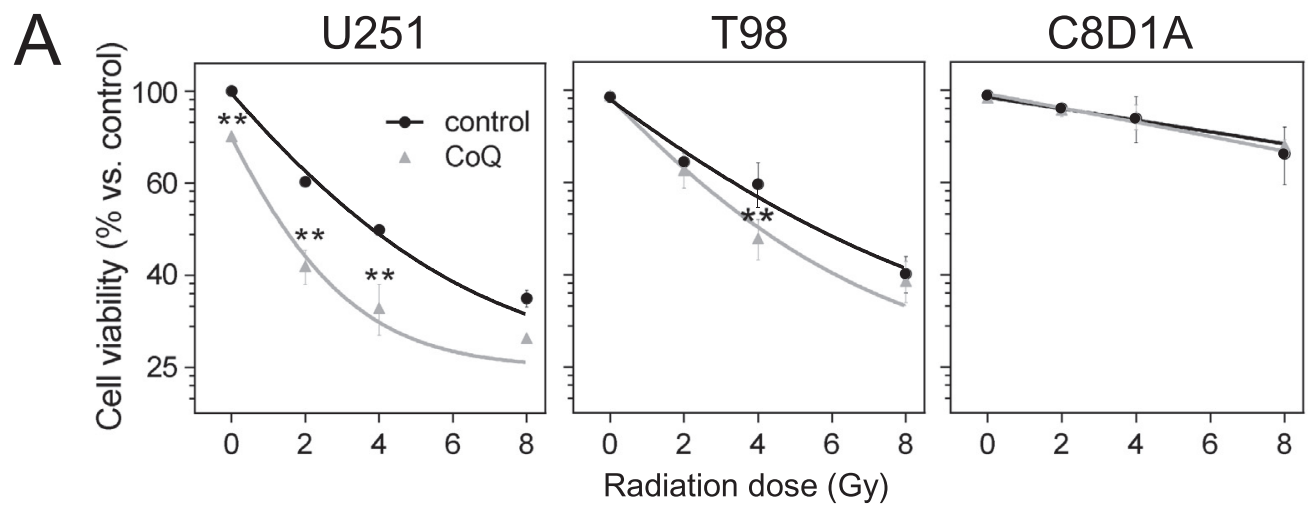

B
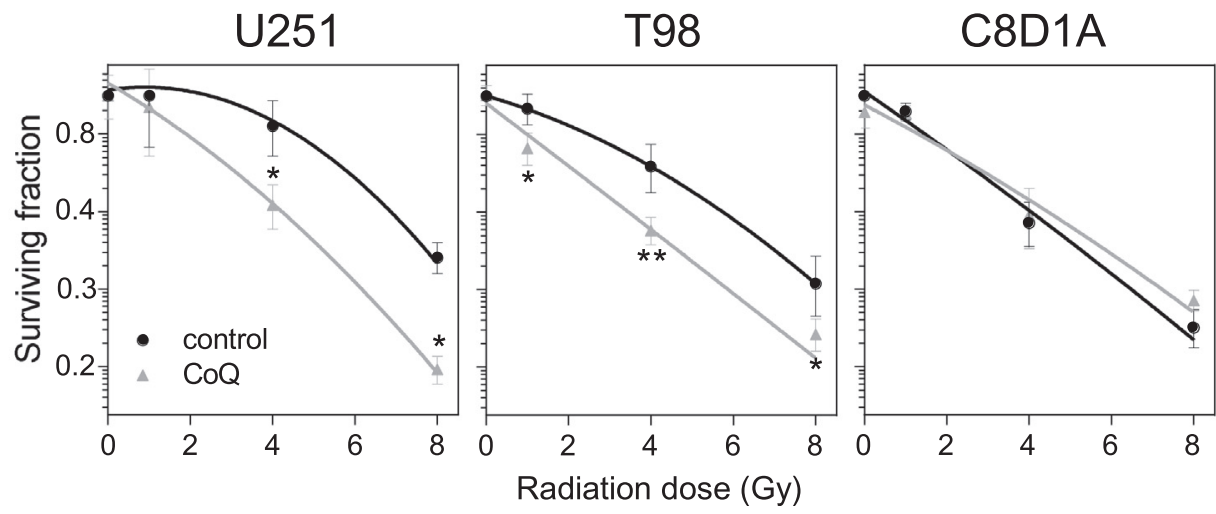

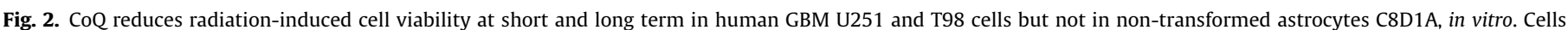

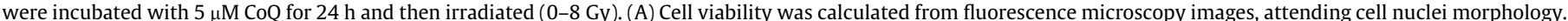

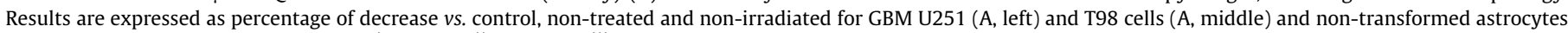

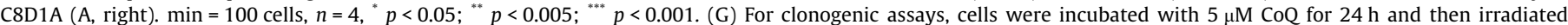

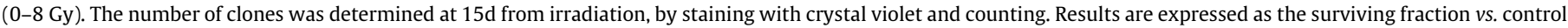
non-treated and non-irradiated for GBM U251 (B, left) and T98 cells (B, middle) and non-transformed astrocytes C8D1A (B, right). $n=4,{ }^{*} p<0.05 ;{ }^{* *} p<0.005$.

U251 and T98 cells, whereas it was not affected in C8D1A cells (Fig. 4C-E). Neither SOD1 nor NQO1 was altered in U251 cells (Fig. 4C).

\section{CoQ regulates the synthesis of glutathione}

Glutathione is one of the main cellular antioxidants, being its synthesis upregulated during oxidative stress [16]. An increased level of oxidants such as $\mathrm{H}_{2} \mathrm{O}_{2}$ causes short-term falls in intracellular GSH, which is associated with higher levels of GSSG [16]. Our results in human U251 cells show that the level of GSH was neither altered by treatment with vehicle (control) nor with CoQ (Supplementary Fig. 4A, left). However, CoQ significantly decreased the level of GSSG (Supplementary Fig. 4A, middle), which resulted in a decrease in GSSG/GSH ratio (Supplementary Fig. 4A, right) and in a smaller glutathione-antioxidant capacity of CoQ-treated cells. This change in the whole glutathione pool could be due to the lowering of critical amino acids essential for the synthesis of the antioxidant, glutamate, glycine, serine and glutamine, all of them reduced by $42 \%, 52 \%, 50 \%$ and $40 \%$, respectively, in CoQ-treated vs. control cells (Supplementary Fig. 4B).

\section{CoQ potentiates $T M Z$ in the radiosensitization of human GBM cells}

TMZ, the standard chemotherapeutical in the clinical management of GBM, is known to have also a radiosensitizing effect [2]. We have analyzed the interaction between TMZ and CoQ on radiation-induced cytotoxicity in U251 and T98 cells compared to non-transformed C8D1A astrocytes. In U251 cells, CoQ or TMZ alone increased radiation-induced apoptosis by $13 \%$ and $17 \%$, respectively, whereas the combined treatment with CoQ and TMZ increased radiation-induced apoptosis in $28 \% v$ s. cells treated with vehicle, at $4 \mathrm{~Gy}$ with a fractional effect of 0.58 and $\mathrm{CI}$ of 0.22 showing strong synergism (Supplementary Fig. 5, left and Supplementary Table 1). In T98 cells, CoQ or TMZ alone increased radiation-induced apoptosis by $12 \%$ and $6 \%$, being CoQ + RT-medi ated effect more effective than TMZ + RT. Combined treatment with CoQ and TMZ increased radiation-induced apoptosis in $17 \%$ vs. cells treated with vehicle, at $4 \mathrm{~Gy}$ with a fractional effect of 0.51 and $\mathrm{CI}$ of 0.68 showing moderate synergism (Supplementary Fig. 5, middle and Supplementary Table 1). No difference was found between treatments for non-transformed C8D1A astrocytes (Supplementary Fig. 5, right).

\section{Discussion}

Radioresistance is a hallmark of GBM [6-10]. Even with the current treatment that encompasses maximal function-preserving surgery followed by TMZ concomitant with radiotherapy (Stupp's protocol), the tumor regrows within the radiation field $[1,3-5]$. Radioresistance is orchestrated by multiple and interconnected factors, including the recruitment of different antioxidant systems due to the overproduction of high levels of $\mathrm{O}_{2}^{--}$and the glycolytic metabolism and $[1,6,7]$. Here we describe a novel combined treatment for GBM, in vitro, using $\mathrm{CoQ}$ as radiosensitizer, targeting mitochondrial $\mathrm{O}_{2}^{--}$and $\mathrm{H}_{2} \mathrm{O}_{2}$, diminishing the total antioxidant cell capacity by reducing the level of catalase, SOD2, glutathione and 

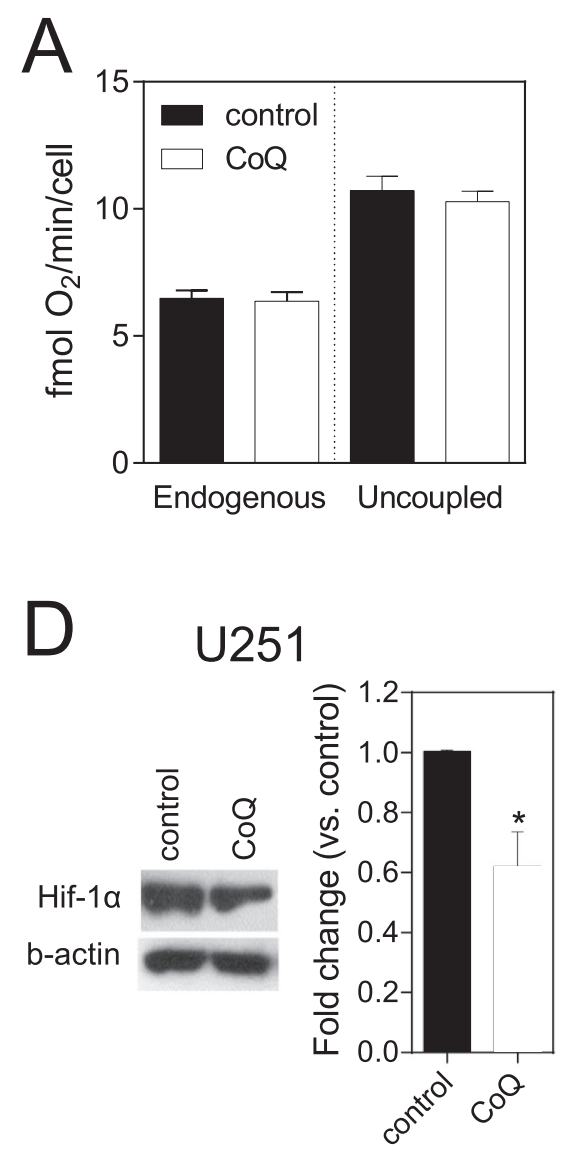
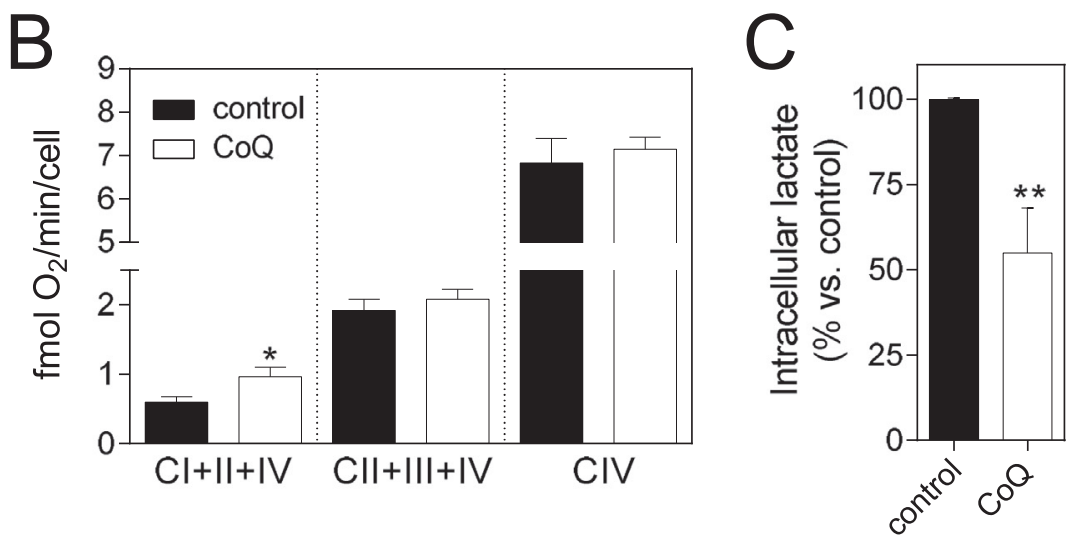

E
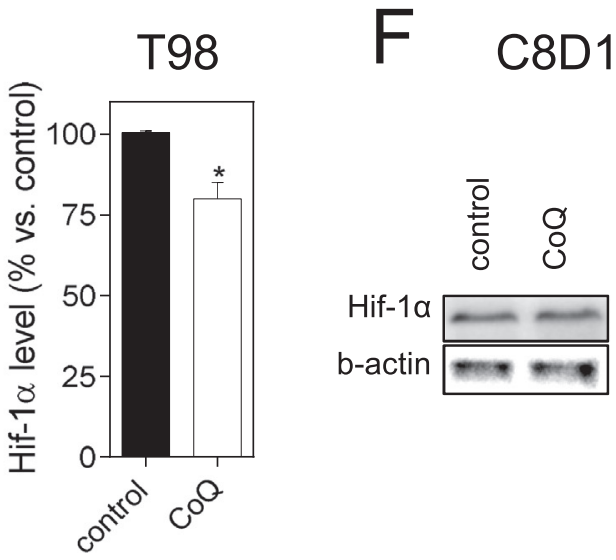

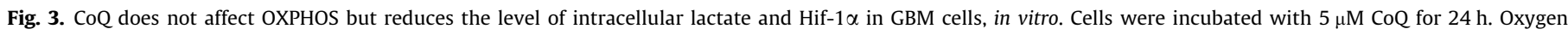

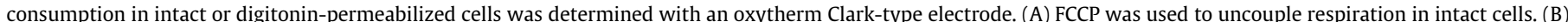

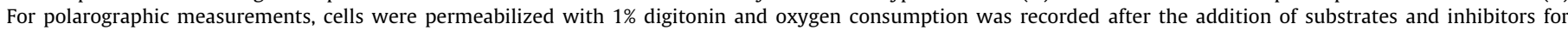

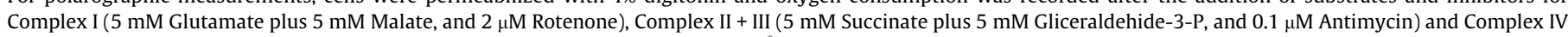

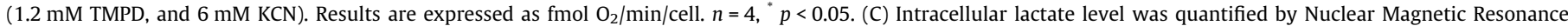

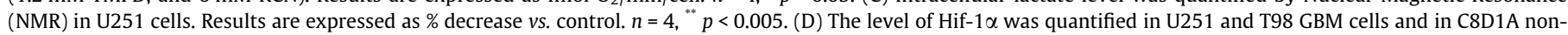
transformed astrocytes by immuno-techniques with an anti- Hif- $1 \alpha$ antibody. $n=4,{ }^{* *} p<0.05$.

lactate, by mechanisms involving a reduction in the level of Hif- $1 \alpha$, improving the overall response to radiotherapy and TMZ in vitro, which targets specifically tumor cells without affecting nontransformed astrocytes.

CoQ is a lipophilic antioxidant that crosses the blood-brain barrier $[20,26]$. Exogenous CoQ is first accumulated in the endolysosomal compartment, and then rapidly becomes incorporated to mitochondria-associated membranes and mitochondria [26]. In this organelle, CoQ participates in oxidative phosphorylation under normal conditions, whereas under pathological conditions, as in tumor cells, it diminishes the high levels of $\mathrm{O}_{2}^{--}$generated by complex I [12]. In this context, our results show that the preincubation of GBM cells with CoQ diminished by 50\% the level of mitochondrial $\mathrm{O}_{2}^{-}$and, in parallel, the level of $\mathrm{H}_{2} \mathrm{O}_{2}$ (Fig. $1 \mathrm{~A}$ and $\mathrm{B})$, increasing oxygen consumption associated with mitochondrial complex I, without affecting the overall respiration rate (Fig. $3 \mathrm{~A}$ and $\mathrm{B}$ ). Since complex I is considered to be one of the main cellular sources of ROS production and both the increase and the decrease in its enzymatic activity have been previously related to this process [27], our results could agree with a model that is associated with the reduction in oxidative stress by favoring the nonaccumulation of reducing power.

Elevated $\mathrm{O}_{2}^{--}$and $\mathrm{H}_{2} \mathrm{O}_{2}$ levels are toxic to normal cells [28]. However, cancer cells overcome high levels of ROS by turning on multiple antioxidant systems that also protect cells from further pro-oxidant stimuli, as radiation [28]. Cancer cells take advantage of the situation since $\mathrm{O}_{2}^{-}$and $\mathrm{H}_{2} \mathrm{O}_{2}$ can also sustain proliferation [29]. Our results indicate that CoQ can deactivate several of these antioxidant systems, reflected by a decrease in the total cell antioxidant capacity.

We have shown that CoQ reduces by almost $50 \%$ the level of intracellular lactate (Fig. 3C), possibly regulating the Warburg effect. Intracellular lactate has an antioxidant role by dampening free oxygen radicals induced by radiation [14,19]. Thus, CoQmediated lactate decrease seems to contribute to the elevated $\mathrm{O}_{2}^{--}$and $\mathrm{H}_{2} \mathrm{O}_{2}$ levels induced by radiotherapy (Fig. $1 \mathrm{~A}$ and $\mathrm{B}$ ), leading to an enhanced DNA damage and apoptosis (Supplementary Fig. 2). Moreover, lactate is one of the main energy sources of GBM cells $[14,30]$. Thus, the CoQ-mediated lowering of the lactate levels may be associated with the small but significant decrease in cell viability in non-irradiated $v s$. non-treated cells (Fig. 2A, left). This effect could be related to the decrease observed in Hif- $1 \alpha$ level after incubation with CoQ (Fig. 3D and E). Multiple evidences pointed toward Hif- $1 \alpha$ as the main driver for glycolytic metabolism and radioresistance [31-33]. Hif-1 $\alpha$ changes glucose metabolism toward a glycolytic phenotype. Indeed, the inhibition of Hif$1 \alpha$ results in a decreased rate in glucose uptake, lactate production and an increase in oxygen consumption, which denotes an enhanced mitochondrial oxidation [34,35]. In this sense, our results indicate that $\mathrm{CoQ}$ is reducing the level of Hif- $1 \alpha$ (Fig. 3D 
A

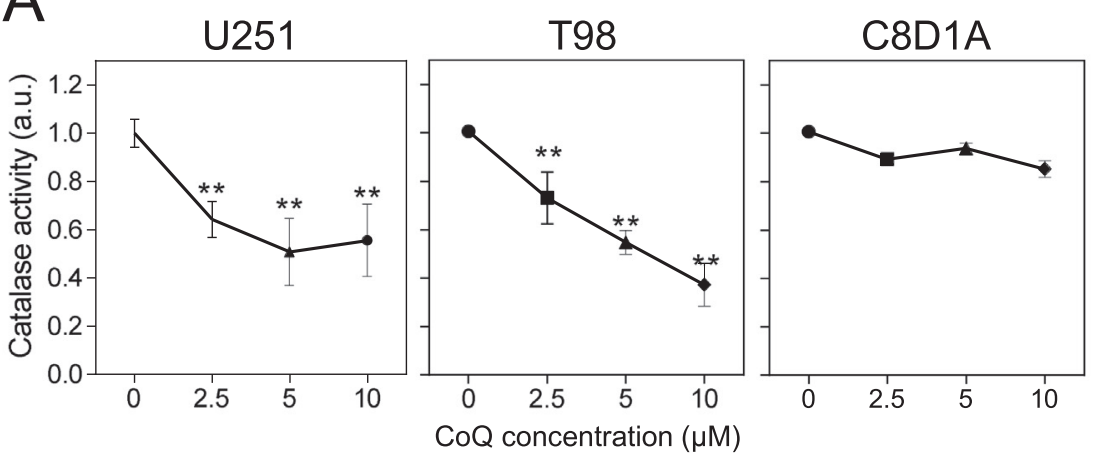

B

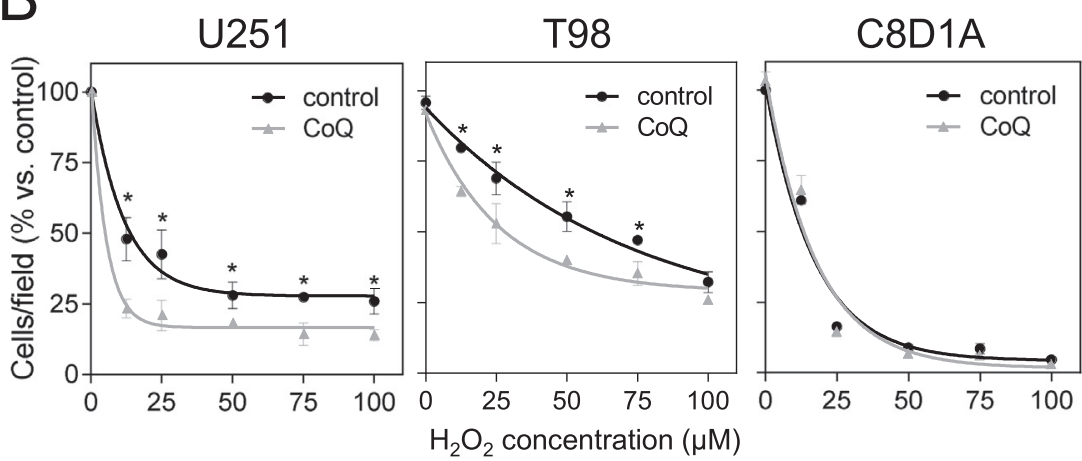

C

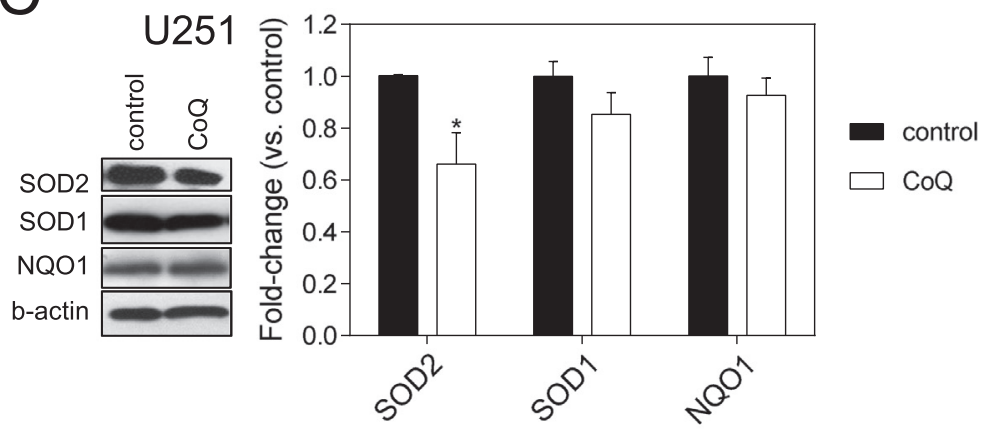

D

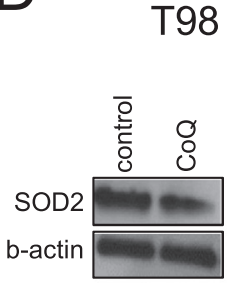

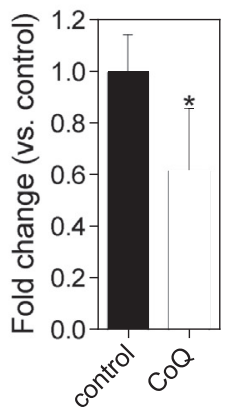
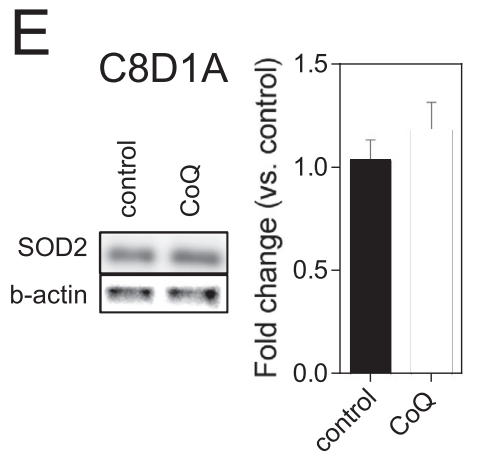

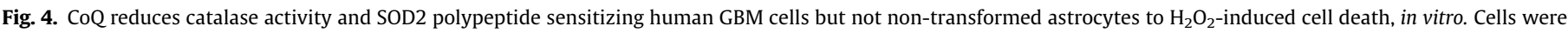

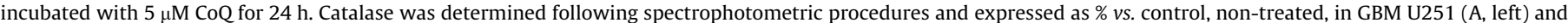

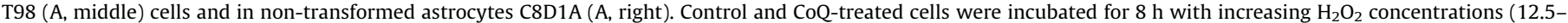

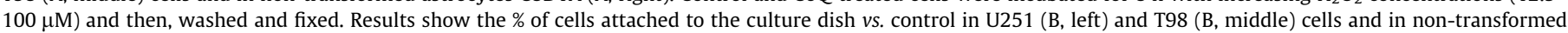

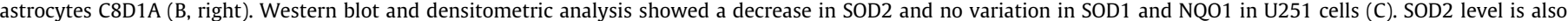
decreased in T98 cells (D) but unaffected in non-transformed C8D1A astrocytes (E). $n=4,{ }^{*} p<0.05 ;{ }^{* *} p<0.005$.

and $\mathrm{E}$ ), which agrees with the reduction observed in the level of lactate (Fig. 3C), probably also related to the slight increase in oxygen consumption associated with the mitochondrial complex I (Fig. 3A). Furthermore, $\mathrm{H}_{2} \mathrm{O}_{2}$ is sufficient to stabilize HIF-1 $\alpha$ protein under normoxia [36,37] and preincubation of U251 and T98 cells with $\mathrm{CoQ}$ reduced the levels of $\mathrm{H}_{2} \mathrm{O}_{2}$. As a whole, $\mathrm{CoQ}$ contributes to radiosensitize GBM cells through modulation of Hif- $1 \alpha$, lactate level and probably mitochondrial respiration. 
A search in the TCGA and Murat series included within the Oncomine database (https://www.oncomine.org/resource/ login. html) shows that catalase and SOD2 levels are increased in glioblastoma vs. normal brain (Supplementary Figs. 6 and 7) whereas SOD1 and NQO1 levels are not altered (Supplementary Figs. 8 and 9). Our results show a decrease in catalase activity and $44 \%$ reduction in SOD2 polypeptide level in human GBM cells but not in non-transformed astrocytes (Fig. 4C-E). Conversely, CoQ neither alters the levels of SOD1 nor NQO1 (Fig. 4C). CoQ has been shown to inhibit deregulated catalase activity and SOD2 levels in a model of DMBA induced breast cancer [38] as well as in a model of diabetic rats, a non-tumor disease with a strong oxidative component [39]. To our knowledge, there was no previous evidence that CoQ reduces catalase and SOD2 levels in GBM cells. It is known that an increase in catalase and SOD2 activities is linked to radioresistance in human GBM U251 cells [6], and that the inhibition of the enzymes sensitizes rat glioma cells to apoptosis induced by pro-oxidant injuries [40]. Lessening of catalase and SOD2 by CoQ combined with the reduced intracellular lactate level could be related to the radiosensitization and potentiation of both, short and long-term radiation-induced apoptosis reported here (Fig. 2A and $\mathrm{B}$ ).

GSH is the most abundant non-enzymatic antioxidant molecule in the cell, essential for cell survival and redox homeostasis [28]. It protects the cell against $\mathrm{O}_{2}^{-}$and $\mathrm{H}_{2} \mathrm{O}_{2}$-induced oxidation, but it is likewise involved in cancer cell-resistance to ionizing radiation [16]. Indeed, the level of GSH is negatively correlated to the sensitivity of brain tumors to radiation [17]. There is no previous evidence of GSH regulation by CoQ in tumor pathologies. However, CoQ reduced the level of hepatic GSH triggered by ischemiareperfusion in a rat model of the disease [41]. Our results show that CoQ clearly diminished the oxidized form of glutathione, GSSG, and the ratio GSSG/GSH (Fig. 3G). Thus, CoQ decreased the total and effective amounts of glutathione, probably through inhibition of glutamate, glycine, serine and glutamine levels (Supplementary Fig. 4), all of them being key precursor metabolites of glutathione synthesis [28]. Our results show that the reduction in total glutathione level could be involved in the sensitization of GBM cells to pro-oxidant stimuli, as radiation (Fig. 1). Glutathione is also related to the TMZ-induced bystander effect described in GBM previously [18]. TMZ is the standard chemotherapeutic for the treatment of GBM, concomitant with surgical resection and/or radiotherapy $[2,3]$. While many mechanisms contribute to the development of resistances, it is known that small fractions of resistant cells can induce a general resistance to temozolomide by mechanisms that involve an increase in the antioxidant machinery [18]. This effect can be reversed by glutathione-depleting agents. Our results show that $\mathrm{CoQ}$ reduces the effective amount of glutathione, sensitizing, in parallel, GBM cells, but not astrocytes, to TMZ in non-irradiated cells (Supplementary Fig. 5), which suggests that this action could be due to the mechanism reported hitherto [15]. It is interesting to note that computer simulations of mathematical models of GBM growth have predicted that the effect of an antioxidant therapy with the properties reported here may have a major effect on the evolution of the disease when other factors are taken into account [42].

Our results reported herein provide the first evidence, in vitro, that CoQ radiosensitizes and potentiates TMZ cytotoxicity, inducing apoptosis in human GBM cells, without affecting normal astrocytes, by regulating, simultaneously, intracellular lactate and Hif$1 \alpha$, catalase activity and SOD2 and glutathione levels. Thus CoQ, known as antioxidant, can diminish the total antioxidant cell capacity deactivating the cell antioxidant machinery. CoQ emerges as an attractive molecule for combined therapies with radiation and TMZ aimed to improve the prognosis of patients suffering this, nowadays, fatal pathology.

\section{Funding}

The authors' work was supported by Grants 220,020,351 (James S. MacDonnell Foundation), GE20112221 (Universidad de CastillaLa Mancha), PPII-2014-010-P (Junta de Comunidades de Castilla-La Mancha), 220,020,351 (Ministerio de Economía y Competitividad), MTM2015-71200-R (MINECO-FEDER) and SAF2016-79311-R (MINECO-FEDER). M.V.G. acknowledges Ministerio de Economia y Competitividad (MINECO) for participation in the Ramon y Cajal program and for financial support (CTQ2014-54987-P). The funders had no role in study design, data collection and analysis, decision to publish, or preparation of the manuscript.

\section{Authors' contributions}

JF-R performed $\mathrm{O}_{2}^{--}$and $\mathrm{H}_{2} \mathrm{O}_{2}$ measurements, cell viability, clonogenic assays, cell-sensitivity to exogenous $\mathrm{H}_{2} \mathrm{O}_{2}$ and western blot and performed statistical analysis. RS-M quantified DNA damage and apoptosis and performed statistical analysis. CMN-V determined the total antioxidant cell capacity. G-F analyzed oxygen consumption. AM-G and VMP-G fitted the curves for cell viability and participated in drafting the manuscript. MV-G and MM identified and quantified intracellular metabolites by NMR. JA analyzed NQO1 by western blot. EL, JA-G and AG-A performed cells irradiation. MP quantified glutathione levels. JRP determined catalase activity. LPR participated in experimental design and data analysis. JMV participated in data analysis and drafting the manuscript. FJA participated in experimental design, data analysis and drafting the manuscript. MD-P conceived the study, designed the experiments, analyzed the data and wrote the manuscript.

\section{Acknowledgements}

We thank Kaneka Corporation, who generously provided the CoQ used in these experiments. JF-R acknowledges Excelentísima Diputación de Ciudad Real. MVG acknowledges Albacete Science and Technology Park.

Thanks to RSM, my partner in life and vocation, for her dedication to this and other works even during a great battle against cancer. Death 07/24/2016, rest in peace.

\section{Conflict of interest statement}

None declared.

\section{Appendix A. Supplementary data}

Supplementary data associated with this article can be found, in the online version, at https://doi.org/10.1016/j.radonc.2018.04. 033.

\section{References}

[1] Van Meir EG, Hadjipanayis CG, Norden AD, Shu HK, Wen PY, Olson JJ. Exciting new advances in neuro-oncology: the avenue to a cure for malignant glioma. CA 2010;60:166-93.

[2] Carlson BL, Grogan PT, Mladek AC, Schroeder MA, Kitange GJ, Decker PA, et al. Radiosensitizing effects of temozolomide observed in vivo only in a subset of O6-methylguanine-DNA methyltransferase methylated glioblastoma multiforme xenografts. IJROBP. 2009;75:212-9.

[3] Stupp R, Dietrich P-Y, Ostermann Kraljevic S, Pica A, Maillard I, Maeder P, et al. Promising survival for patients with newly diagnosed glioblastoma multiforme treated with concomitant radiation plus temozolomide followed by adjuvant temozolomide. J Clin Oncol 2002;20:1375-82.

[4] Kioi M, Vogel H, Schultz G, Hoffman RM, Harsh GR, Brown JM. Inhibition of vasculogenesis, but not angiogenesis, prevents the recurrence of glioblastoma after irradiation in mice. J Clin Invest 2010;120:694-705. 
[5] Liang BC, Thornton AF, Sandler HM, Greenberg HS. Malignant astrocytomas: focal tumor recurrence after focal external beam radiation therapy. J Neurosurg 1991;75:559-63.

[6] Lee H-C, Kim D-W, Jung K-Y, Park I-C, Park M-J, Kim M-S, et al. Increased expression of antioxidant enzymes in radioresistant variant from U251 human glioblastoma cell line. Int J Mol Med 2004;13:883-7.

[7] Deighton RF, Le Bihan T, Martin SF, Gerth AM, McCulloch M, Edgar JM, et al. Interactions among mitochondrial proteins altered in glioblastoma. J NeuroOncol 2014;118:247-56.

[8] Shen H, Hau E, Joshi S, Dilda PJ, McDonald KL. Sensitization of glioblastoma cells to irradiation by modulating the glucose metabolism. Mol Cancer Therot 2015; 14:1794-804.

[9] Liu R, Fan M, Candas D, Qin L, Zhang X, Eldridge A, et al. CDK1-Mediated SIRT3 activation enhances mitochondrial function and tumor radioresistance. Mol Cancer Therot 2015;14:2090-102.

[10] You WC, Chiou SH, Huang CY, Chiang SF, Yang CL, Sudhakar JN, et al. Mitochondrial protein ATPase family, AAA domain containing $3 \mathrm{~A}$ correlates with radioresistance in glioblastoma. Neuro-Oncol 2013;15:1342-52.

[11] Marin-Valencia I, Yang C, Mashimo T, Cho S, Baek H, Yang X-L, et al. Analysis of tumor metabolism reveals mitochondrial glucose oxidation in genetically diverse human glioblastomas in the mouse brain in vivo. Cell Metab. 2012;15:827-37.

[12] Murphy Michael P. How mitochondria produce reactive oxygen species. Biochem J 2009;417.

[13] Fiaschi T, Chiarugi P. Oxidative stress, tumor microenvironment, and metabolic reprogramming: a diabolic liaison. International J Cell Biol 2012;2012:1-8

[14] Hirschhaeuser F, Sattler UGA, Mueller-Klieser W. Lactate: a metabolic key player in cancer. Cancer Res 2011;71:6921-5.

[15] Matsumoto H, Takahashi A, Ohnishi T. Nitric oxide radicals choreograph a radioadaptive response. Cancer Res 2007;67:8574-9.

[16] Ortega AL, Mena S, Estrela JM. Glutathione in cancer cell death. Cancers 2011;3:1285-310.

[17] Kudo H, Mio T, Kokunai T, Tamaki N, Sumino K, Matsumoto S. Quantitative analysis of glutathione in human brain tumors. J Neurosurg 1990;72:610-5.

[18] Kohsaka S, Takahashi K, Wang L, Tanino M, Kimura T, Nishihara H, et al. Inhibition of GSH synthesis potentiates temozolomide-induced bystander effect in glioblastoma. Cancer Lett 2013;331:68-75.

[19] Groussard C, Morel I, Chevanne M, Monnier M, Cillard J, Delamarche A. Free radical scavenging and antioxidant effects of lactate ion: an in vitro study. J Appl Physiol 2000;89:169-75.

[20] Mitsui J, Koguchi K, Momose T, Takahashi M, Matsukawa T, Yasuda T, et al Three-year follow-up of high-dose ubiquinol supplementation in a case of familial multiple system atrophy with compound heterozygous COQ2 mutations. Cerebellum 2017;16:664-72.

[21] Hofhaus G, Shakeley RM, Attardi G. Use of polarography to detect respiration defects in cell cultures. Methods Enzymol 1996:264:476-83.

[22] Cordoba-Pedregosa Mdel C, Villalba JM, Gonzalez-Aragon D, Bello RI, Alcain FJ. Cellular density and cell type are the key factors in growth inhibition induced by 2,5bis [1-aziridinyl]-1,4 benzoquinone (DZQ). Anticancer Res 2006;26:3535-40.

[23] Torres-Lista V, Parrado-Fernandez C, Alvarez-Monton I, Frontinan-Rubio J, Duran-Prado M, Peinado JR, et al. Neophobia, NQO1 and SIRT1 as premorbid and prodromal indicators of $\mathrm{AD}$ in 3xTg-AD mice. Behav Brain Res 2014;271:140-6.

[24] Duran-Prado M, Frontinan J, Santiago-Mora R, Peinado JR, Parrado-Fernandez C, Gomez-Almagro MV, et al. Coenzyme Q10 protects human endothelial cells from beta-amyloid uptake and oxidative stress-induced injury. PLoS One 2014:9:e109223.

[25] Dacevic M, Isakovic A, Podolski-Renic A, Isakovic AM, Stankovic T, Milosevic Z, et al. Purine nucleoside analog-sulfinosine modulates diverse mechanisms of cancer progression in multi-drug resistant cancer cell lines. PLoS One 2013;8: e54044.

[26] Fernandez-Ayala DJ, Brea-Calvo G, Lopez-Lluch G, Navas P. Coenzyme Q distribution in HL-60 human cells depends on the endomembrane system. BBA 2005;1713:129-37.

[27] Pitkanen S, Robinson BH. Mitochondrial complex I deficiency leads to increased production of superoxide radicals and induction of superoxide dismutase. J Clin Invest 1996;98:345-51.

[28] Gorrini C, Harris IS, Mak TW. Modulation of oxidative stress as an anticancer strategy. Nat Rev Drug Discov 2013;12:931-47.

[29] Janssen-Heininger YM, Mossman BT, Heintz NH, Forman HJ, Kalyanaraman B, Finkel $\mathrm{T}$, et al. Redox-based regulation of signal transduction: principles, pitfalls, and promises. Free Radical Biol Med 2008;45:1-17.

[30] Sonveaux P, Vegran F, Schroeder T, Wergin MC, Verrax J, Rabbani ZN, et al. Targeting lactate-fueled respiration selectively kills hypoxic tumor cells in mice. J Clin Invest 2008;118:3930-42.

[31] Galeffi F, Turner DA. Exploiting metabolic differences in glioma therapy. Curr Drug Discov Technol 2012;9:280-93.

[32] Marampon F, Gravina GL, Zani BM, Popov VM, Fratticci A, Cerasani M, et al. Hypoxia sustains glioblastoma radioresistance through ERKs/DNA-PKCs/HIF1alpha functional interplay. IInt J Oncol 2014;44:2121-31.

[33] Meijer TW, Kaanders JH, Span PN, Bussink J. Targeting hypoxia, HIF-1, and tumor glucose metabolism to improve radiotherapy efficacy. Clin Cancer Res 2012;18:5585-94.

[34] Baker LC, Boult JK, Walker-Samuel S, Chung YL, Jamin Y, Ashcroft M, et al. The HIF-pathway inhibitor NSC-134754 induces metabolic changes and antitumour activity while maintaining vascular function. $\mathrm{Br} \mathrm{J}$ Cancer 2012;106:1638-47.

[35] Cairns RA, Papandreou I, Sutphin PD, Denko NC. Metabolic targeting of hypoxia and HIF1 in solid tumors can enhance cytotoxic chemotherapy. PNAS 2007; 104:9445-50

[36] Brunelle JK, Bell EL, Quesada NM, Vercauteren K, Tiranti V, Zeviani M, et al. Oxygen sensing requires mitochondrial ROS but not oxidative phosphorylation. Cell Metab 2005;1:409-14.

[37] Guzy RD, Hoyos B, Robin E, Chen H, Liu L, Mansfield KD, et al. Mitochondrial complex III is required for hypoxia-induced ROS production and cellular oxygen sensing. Cell Metab 2005;1:401-8.

[38] Perumal SS, Shanthi P, Sachdanandam P. Combined efficacy of tamoxifen and coenzyme Q10 on the status of lipid peroxidation and antioxidants in DMBA induced breast cancer. Mol Cell Biochem 2005;273:151-60.

[39] Coldiron Jr AD, Sanders RA, Watkins 3rd JB. Effects of combined quercetin and coenzyme $\mathrm{Q}(10)$ treatment on oxidative stress in normal and diabetic rats. J Biochem Mol Toxicol 2002;16:197-202.

[40] Smith PS, Zhao W, Spitz DR, Robbins ME. Inhibiting catalase activity sensitizes 36B10 rat glioma cells to oxidative stress. Free Radical Biol Med 2007; 42:787-97.

[41] Ito K, Miwa N, Hagiwara K, Yano T, Shimizu-Saito K, Goseki N, et al. Regulation of methionine adenosyltransferase activity by the glutathione level in rat liver during ischemia-reperfusion. Surg Today 1999;29:1053-8.

[42] Martinez-Gonzalez A, Duran-Prado M, Calvo GF, Alcain FJ, Perez-Romasanta LA, Perez-Garcia VM. Combined therapies of antithrombotics and antioxidants delay in silico brain tumour progression. Math Med Biol 2015;32(3):239-62. 